\title{
Developing Ambidextrous Routines in the IT Service Provider Industry
}

\author{
Dragos Vieru \\ TÉLUQ University \\ dragos.vieru@teluq.ca stefan.klein@wi.uni-muenster.de
}

\author{
Simon Bourdeau \\ ESG-UQÀM \\ bourdeau.s@uqam
}

\author{
Jean-Bosco Ntakirutimana \\ UQO \\ ntaj06@uqo.ca
}

\begin{abstract}
This study explores ambidextrous practices and distinctive leadership styles in interorganizational settings of two German medium sized IT service providers. We draw on the theory of routines-as-practices and on the organizational ambidexterity literature to analyze organizational practices aiming at both potential for change (exploration) and stability (exploitation). We identify two distinct modes of contextual ambidexterity, whereby one capability is used to improve the other, i.e. 'exploration for exploitation', an orientation towards continually improving the quality of the service delivery, and 'exploration through exploitation', an approach of project-driven learning. We highlight and classify a multi-layered repertoire of ambidextrous routines across the three levels of analysis: leadership, project team, and client relations. Our findings illustrate elaborate management repertoires of interventions with respect to culture, structures, policies or practices, which are aligned with the ecosystem within which both companies are operating.
\end{abstract}

\section{Introduction}

There is a general consensus that organizations need to both explore and exploit successfully to survive and thrive [16, 32]. Ambidexterity embodies the idea that enduring success of a firm depends on its ability to exploit current capabilities while concurrently exploring new opportunities [24]. Exploitation focuses on efficiency, increasing productivity, and extending operational excellence. Exploration concentrates on innovation, building emerging capabilities and creating workable business options for the future.

Ambidexterity is the rare ability to combine both while mitigating the tensions between freedom and resources needed for exploration and the discipline and rigor required for exploitation in pursuit of competitiveness [27]. Organizational ambidexterity is usually analyzed from two perspectives. One is structural ambidexterity, which uses different organizational structures and strategies to differentiate activities of exploitation and exploration [15]. The second is contextual ambidexterity which represents the capacity of an organization to balance exploitative and explorative tasks without separating them [20].

Achieving ambidexterity is challenging and involves activities that require fundamentally different processes, routines, structures, and incentives [15]. Employees are asked to comply with established organizational procedures that represent the core of the organizations' capability to perform and to deliver consistent quality (exploitation). At the same time, they are also encouraged to explore new, innovative ways of working, experiment with new routines and engage in processes of continuous innovation.

The concept of ambidexterity has originally been developed in innovation studies, with an emphasis on large, production-oriented enterprises and as a response to the innovator's dilemma [43]. This raises three issues: a) the transfer of the concept to an information systems context, b) the exploration of ambidexterity in an industry setting that is distinct from manufacturing, but core to IS and c) the exploration of distinctive ambidextrous practices in the context of SMEs.

While the idea of combining exploitation and exploration appears commonsensical once articulated, the implementation in practice - as our study clearly shows - is far from obvious and an ongoing challenge for both management and the individuals striving to achieve ambidexterity. Finding the balance between the two and developing practices to consistently deliver on both fronts actually is highly context specific and requires high levels of proficiency and indeed excellence.

Given the high innovation pace in the IT sector, the relevance of ambidextrous competencies is obvious. However, IT services companies may be seen as unlikely candidates for a study on ambidexterity, as service delivery is often regarded as more repetitive, performance focuses with an inherent emphasis on project execution and delivery, and thus mainly exploitative. However, the dynamic environments of IT services that are characterized by technology-driven short innovation cycles [40], increasing requirements to develop new services in response to customers' changing demands [7], and market dynamism encourages firms 
to innovate and strengthen their technological capabilities by following new market opportunities [42]. We have been able to show that management and individuals have been quite innovative to not only to achieve both exploitation and exploration but also to combine and integrate them in novel ways.

Extant literature suggests that ambidexterity may be achieved only by some organizations. Some researchers even argue that small and medium-sized enterprises (SME) should not attempt to pursue ambidexterity as this could lead to poor performance, given their limited resources as compared to those in larger firms [9]. However, just like larger firms, SMEs must deal with competitive pressures may actually be well positioned to achieve organizational ambidexterity [23]. A balance of explorative and exploitative practices is beneficial to SMEs with fewer accessible resources both internally and externally [31]. However, there is insufficient evidence on how exploration and exploitation occur in SMEs, especially in the IT service sector, and what factors may affect SMEs' capability to balance exploration and exploitation.

Client-facing and vendor-facing interorganizational relations, provide an opportunity for SMEs to extend their resource base and they are the ultimate test of ambidextrous capabilities. We are interested in identifying and analyzing distinctive ambidextrous practices in this specific context (in leadership, project teams' dynamics, and client relations). Further we want to acknowledge the personal commitment required to achieve outstanding levels of ambidextrous competence.

Hence, we are asking: How do small and medium sized organizations in the IT services industry achieve ambidextrous competences?

Attempting to answer this question, our study draws on the theory of routines-as-practices [13] and on the organizational ambidexterity literature. The term routines refers to the means by which organizations accomplish their work [12]. The term practice refers to the coordinated activities in a specific organizational context [13]. We adopt the view of organizational routines as sources of flexibility and change [12, $14]$, where routines are seen as generative systems comprised of two interacting parts: ostensive and performative. We consider practices (performative aspects) and patterns of practices (ostensive aspects) as the mutually constitutive parts of organizational routines.

Theorizing routines as practices enables us to shed light on the outcomes of organizational practices and both the potential for change (exploration) and the work that ensure stability (exploitation) [13].
A particular aspect of our study and the industry segment, is the prominence of interorganizational relations: client projects as well as engagement with the technology vendors are both used as settings for exploration. The organizational (institutional) context of collaboration is linked to the individual level of managers and consultants and their counterparts in the client firm. While the firm aims for ambidexterity as an outcome of their operations (operational efficiency and innovation), this outcome is the result of individual (and team) practices of balancing the requirements of billable hours with innovation focused routines (e.g. individual research, cross-project learning. etc.).

A focus on daily routines can thus bring to the fore such relationships, interdependencies, coordination questions and leadership implications during the process of interorganizational cross-boundary collaboration and knowledge sharing. From a processual viewpoint we look at the dynamics of ostensive and performative aspects of routines and the development of ambidextrous competencies based on leadership practices that shape routines of the project teams and their relations with the clients.

The routines-as-practices perspective allows us to go beyond the traditional strategic, economic and cultural perspectives used in the ambidexterity literature, to identify and analyze the connections between specific explorative or exploitative processes and practices. Thus, we have identified patterns of ambidextrous routines, specifically exploration for, and through exploitation.

We chose to adopt a theory building from case studies approach [10] with theoretical replication. We conducted multi-case study of two German small and medium sized IT service providers (ITSP), Noventum and viadee ${ }^{1}$, for which balancing exploitation (essential for the financial bottom line) and exploration (a differentiator in the market and an inevitable investment into the future) has become part of their identity and mission.

Conceptually we identified two instances of contextual ambidexterity manifested as: 1 . exploration to (continuously) improve exploitation (exploration for exploitation) and 2. exploration as an integral part of project-based exploitation (exploration through exploitation).

Existing literature suggests that structural and temporal separation [17], meta-routines [1], behavioral contexts [15], and organizational culture [38] are some of the mechanisms that facilitate the implementation of organizational ambidexterity. However, these mechanisms often apply to large firms, but not necessarily to SMEs due to their lack of resources to manage paradoxical processes [23].

${ }^{1}$ www.noventum.de/en; www.viadee.de 
Our research answers to several calls for studies crossing multiple levels of analysis that would show how various structures at the organizational level influence organizational members' ambidextrous practices [4]. Thus, the present study's goal is to contribute to the understanding of individual and organizational ambidexterity in SMEs, specifically in the IT services sector.

\section{Conceptual foundation}

\subsection{Organizational Ambidexterity}

The concept of organizational ambidexterity describes the ability to simultaneously explore and exploit [27]. Organizational ambidexterity is often discussed with reference to its two modalities, namely, structural ambidexterity and contextual ambidexterity.

Structural ambidexterity. The concept of structural ambidexterity advances the idea that organizational structures should divide exploitative and explorative practices into separate organizational units, each with distinct competencies, processes, and cultures, while at the same time implementing a process of integration between exploration and exploitation [27]. In other words, this implies that successful ambidexterity is conditioned by the capability of an organization to have different business units able to focus on operation activities, while others focus on adaptation [3]. Researchers supporting this viewpoint posit that exploration and exploitation are completely different activities that require unique organizational structures, incentives, and management approaches in order for each to be successful.

Contextual ambidexterity. Unlike structural ambidexterity, contextual ambidexterity is an approach that enables organizations to balance exploitative and explorative tasks without separating them [20]. In this perspective, ambidextrous organizations create an organizational context that fosters and encourages the flexibility of employees to use their own judgment in how and when they will efficiently divide their time between the conflicting demands of exploitation and exploration across the same business unit [15]. The contextual ambidexterity approach supports O'Reilly and Tushman's [27] argument that a firm that is capable of exploring and exploiting simultaneously is likely to realize superior performance compared to firms that favor one over the other.

Most theories regarding ambidexterity assume that organizations are large enough to allocate sufficient resources to creating and maintaining an ambidextrous environment. However, the ideal route for SMEs with fewer resources to pursue ambidexterity requires more analysis [31].

\subsection{Interorganizational ambidexterity}

Although most organizational ambidexterity research focuses on the organizational level and below [27], an emerging line of research analyzes how organizations use interorganizational relationships (IOR) to achieve ambidexterity. Empirical studies on technology alliance diversity confirm that new knowledge combinations resulting from links with different partner types shape firms' innovation outcomes [41]. Researchers adopting this perspective suggest that organizations may be able to balance necessary, but conflicting, activities by engaging in IOR. In open innovation processes, organizational boundaries are porous and firms strongly interact with different actors in their environment in search of new ideas [18]. With the need for IOR to be ambidextrous, partnering firms are challenged to establish an organizational design to pursue alignment and adaptation [37].

In this sense, IOR researchers, suggest that external partners play a key role in the development and reinforcement of a firm's exploration and exploitation strategies and in complementing them with new resources [27, 34]. Suggesting that organizations may achieve a better balance of these activities in collaboration than in isolation, it thus seems reasonable to presume that firms engaged in collaboration need an organizational structure that balances exploration and exploitation of their resources.

In the specific context of SMEs, it has been suggested that the combination as well as the accumulation of various resources through the interaction of business partners are means to achieve increased innovation and renewed products and services [36]. Whereas extant studies have mainly focused on the strategic impact of ambidexterity, less attention has been given to 'how' organizations may achieve such ambidexterity concretely in an interorganizational context and researchers have yet to identify and analyze the specific collaborative mechanisms that trigger and affect the contextualized efforts made within an interorganizational collaborative process.

\subsection{Organizational Routines-as-Practices: A Process Perspective}

We adopt a process view of organizational routines. A process perspective sheds light on the dynamic nature of routines by analyzing how routines are performed by actors in specific organizational settings [19]. This perspective demonstrates how action and innovation are all part of routine performances [13] and has the potential to explain how organizational actors are able to balance exploitation and exploration in 
their quest to achieve and sustain contextual ambidexterity. From a processual viewpoint, routines are conceptualized as mindful undertakings [11] that are "recognizable patterns of interdependent actions, involving multiple actors" [12, p. 96]. In this vein, routines represent sets of possible patterns, enabled and constrained by the organizational structures from within which actors are assumed to 'enact' their performances [29, 14]. Organizational routines are fundamentally improvisational [12] and adaptive, as members of an organization adjust their practices in response to the actions of others contributing to their work [13].

Feldman and Pentland [12] have proposed that a routine consists of two interrelated aspects. One aspect, the ostensive, represents "the ideal or schematic form of the routine. It is the abstract, generalized idea of the routine or the routine in principle" [12, p. 101]. For example, a job-hiring routine in an organization will produce "endless variations on the appropriate way to go about hiring people for different kinds of jobs" [28, p. 796-797]. Yet, each of these variations identifies the practices involved as a legitimate and recognizable instantiation of a job-hiring procedure. The other aspect, the performative, "consists of specific actions, by specific people, in specific times and places. It is the routine in practice" [12, p. 101]. Here, the focus on 'practice' enables a process view of organizing that recognizes unfolding routines as involving general and specific interpretations of rules and norms [13]. Routines can be theorized as practices because routines are created through practices and the development of a routine occurs through its enactment (the performative aspect) [13].

Studying routines from a practice perspective "requires engaging with the everyday realities of organizational life that are rich with contingency, multiplicity, and emergence" [13, p. 1249]. This understanding of routines raises two questions in the context of our research: How do actors shape the performative aspects, the ostensive aspects, and their interactions while balancing exploitation and exploration? How these routines sustain organizational ambidexterity?

\section{Research design}

We adopted an explanatory theory-building from cases approach [10]. Following Eisenhardt's [10] methodological recommendations, we anchored our problem definition and preliminary construct specification in extant literature, and we crafted our data collection instruments and protocols on the basis of this literature, following a deductive pattern. This was followed, after our entry in the field, by a "flexible and opportunistic" [10, p. 533] data collection approach, and a within-case and cross-case data analysis, which are inductive in nature. We used a multiple-case design and selected the cases applying a theoretical replication logic, maximizing variation, thus predicting contrasting results but for predictable reasons [39], yet allowing comparison. While we have looked at a larger number of cases to extend our insight into the industry, we focus on two cases, which illustrate ambidextrous competencies particularly well.

\subsection{Sampling}

Large IT vendors have decided to partner with small and medium sized IT service providers (ITSP) to service their small and medium sized clients. The ITSPs typically cover a broad and varied portfolio of services, which may include consulting, software development, customizing, post-merger integration etc. ITSPs typically cover one or more IT vendors, e.g. SAP, Oracle, Microsoft, IBM etc., and are specialized on industries or industry segments and/or business functions. In addition to competing with their peers, they are facing competition from the vendors, who partly address the market themselves, and large, independent IT service providers.

We use two cases, which we regard as successful players in their competitive field: both have been founded more than 20 years ago, both have been certified as 'Great Place to Work ${ }^{\circledR}$ ', , which is evidence of systematic care for employees and employee development.

\subsection{Noventum}

Noventum is a "result-driven thought leader" IT Management Consulting company, which currently has 100 employees. They support DAX-listed (German stock index) clients as well as SMEs "in the IT challenges they are faced with and in their effort to establish a modern company culture. We have a passion for well thought-out strategic analysis and strive for the perfect technical implementation"[26]. Noventum's managing partner emphasizes a "culture of trust and performance" as prerequisite for sustainable success. Noventum puts emphasis on quality across all their activities "personal consultant quality, in communications and in cooperation with our customers, in methodological competence as well as - of course - in all necessary technical and economic aspects" [26].

2 https://www.greatplacetowork.de/ 


\section{3 viadee}

Similar to Noventum, viadee, which has $130 \mathrm{em}-$ ployees, is an IT consultancy firm with an emphasis on the integration of culture, method and industry insight: "We also find suitable solutions for complex requirements because we quickly understand the specifics of your business model. People from the viadee simply fit in better with your business because they are better trained to integrate with social skills into their teams and tasks" [35].

\subsection{Interview guideline and coding}

Interviews were the main method of data collection and were based on a protocol (Table 1) crafted from extant theory and research. In line with our theory building approach, however, we remained open to the exploration of new topics and themes during data collection [10]. Informants were selected using a snowball sampling procedure. We interviewed top and division managers. The interviewees were significant as agents, since they influenced the cross-boundary collaboration process due to their roles, status, power and experience. Seven interviews were conducted on site and lasted between 45 to 90 minutes. The interviews were recorded and transcribed. The coding process started by creating a provisional "start list" of categories based on the extant literature. All of the transcripts were coded using the preliminary set of codes.

Three concepts seemed more pertinent to our study and served as an organizing framework for data analysis. These are: leadership practices, project team practices, and client relations. In line with our theorybuilding objective, we remained open to emerging themes [25]. The revised coding table is presented in Table 2.

Table 1. Structure of the interview protocol and participants

\begin{tabular}{|c|c|c|}
\hline Categories & Themes & Interviewees \\
\hline Background of interviewee & Role, lengths of employment at company & \multirow{6}{*}{ 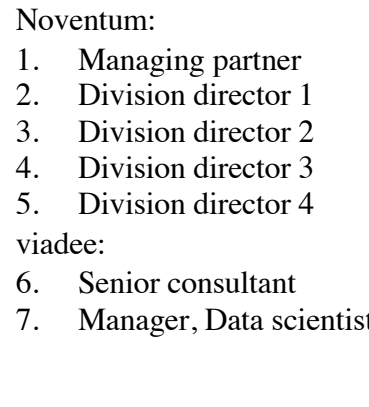 } \\
\hline Company strategy & $\begin{array}{l}\text { Participation, strategy implementation, role of } \\
\text { exploitation vs. exploration }\end{array}$ & \\
\hline Organizational culture & Culture as impeding or enabling ambidexterity & \\
\hline Management behaviors & $\begin{array}{l}\text { The } 4 \text { concepts antecedents to contextual OA - } \\
\text { discipline, stretch, support, trust [6] }\end{array}$ & \\
\hline Strategies to create ambidexterity & $\begin{array}{l}\text { Role models, management style, metrics for in- } \\
\text { novation performance }\end{array}$ & \\
\hline Customer relationship & $\begin{array}{l}\text { Interorganizational approaches to implement } \\
\text { ambidexterity }\end{array}$ & \\
\hline
\end{tabular}

Table 2. Revised coding table

\begin{tabular}{|c|c|c|c|}
\hline Settings & \multirow[t]{2}{*}{ Leadership } & \multirow[t]{2}{*}{ Project team } & \multirow[t]{2}{*}{ Client relation } \\
\hline Routines & & & \\
\hline Exploitation & Recruitment & Performance control & Process design/ step model \\
\hline Exploration & $\begin{array}{l}\text { Competitive intelligence, busi- } \\
\text { ness model pattern research }\end{array}$ & Training & $\begin{array}{l}\text { Knowledge acquisition } \\
\text { from clients }\end{array}$ \\
\hline Contextual ambidexterity & $\begin{array}{l}\text { Leadership style, providing re- } \\
\text { flection space or practices, } \\
\text { Nurturing a learning culture }\end{array}$ & $\begin{array}{l}\text { Dual responsibilities, cross } \\
\text { organizational unit learning }\end{array}$ & \\
\hline Exploration for exploitation & $\begin{array}{l}\text { Pitching exercise facilitation, } \\
\text { empowerment }\end{array}$ & $\begin{array}{l}\text { Sandboxing, exploration ex- } \\
\text { pected / valued by clients }\end{array}$ & Idea prototyping \\
\hline $\begin{array}{l}\text { Exploration through exploi- } \\
\text { tation }\end{array}$ & $\begin{array}{l}\text { Strategically selecting client } \\
\text { projects for exploration }\end{array}$ & $\begin{array}{l}\text { Project-based learning, } \\
\text { knowledge acquisition, agil- } \\
\text { ity, debriefing }\end{array}$ & $\begin{array}{l}\text { Cross-fertilization, } \\
\text { knowledge acquisition }\end{array}$ \\
\hline
\end{tabular}

The outcomes of this analysis constituted the logical chains of evidence. This evidence refers to a detailed description of steps that have been followed, from the research question to the study's conclusion, the tightness and coherence of the process being the foundation of the research [8]. According to the same authors, any study's report should present a logical chain of evidence to allow an external reviewer to follow the derivation of any evidence from the initial research question to the study conclusions and we have responded to this call. Cross-case analysis was conducted by using methods suggested by [10], as the cases were compared to identify similarities and differences between them. 


\subsection{Analysis: Identifying ambidextrous rou- tines and patterns}

Our analysis of ambidextrous routines was contingent on the specific industry setting and the role of the IT service providers. Figure 1 depicts the interorganizational actor constellation.

Typically, IT vendors drive product innovation, which is appropriated and translated by the service providers into consulting and services for their clients. We have found evidence of exploration routines in collaboration with the IT vendors. However, we decided to focus on the richer evidence on the client relationships. The clients confront the service providers with requests and assignments, which require project delivery as well as innovation and development on the service provider side. Also, worth mentioning, the IT service providers have to innovate and reinvent themselves in order to keep an edge in a highly competitive and transparent market.

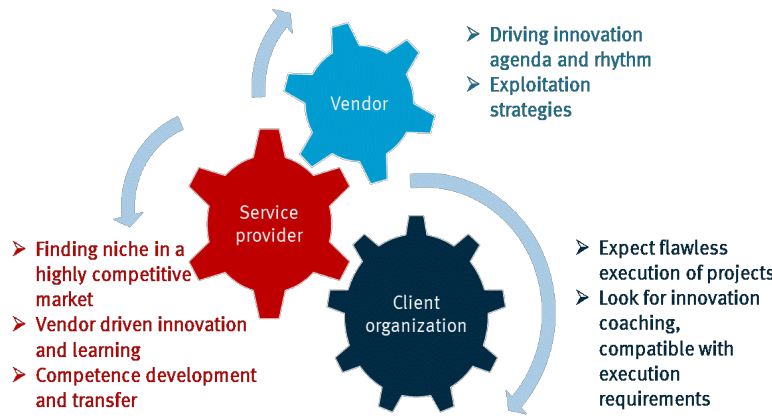

Figure 1. Interorganizational actor constellation

The analysis focused on the roles of exploitation and exploration respectively before concentrating on the practices of exploration for, and through exploitation as specific instances of contextual ambidexterity. We did not find any evidence of a significant structural ambidexterity in either of the two cases.

The interviews have confirmed ostensive and performative dimensions of the ambidextrous practices. However, in the coding of the interviews we are emphasizing the performative dimensions as we did not encounter any example where an ostensive routine was not enacted in a performative manner. Noventum's CEO sees himself as the chief innovator and takes liberties to pursue his innovative practices, some of which are at best loosely related to the service business.

Nevertheless, he has created also an ambidextrous practice based on his exploration: exploitation of exploration, i.e. he has turned his exploration into a service product. viadee has a separate $R \& D$ unit, whose activities are closely linked to the ongoing project work and embedded into the client relations (contextual ambidexterity). Both companies nurture collaborative relationships with local universities and research institutions.

\section{Discussion}

Our study is set in a particular industry segment. IT service providers as consultants typically foreground exploitation, the successful delivery of projects. Yet, exploration is seen as key to service excellence and thus as differentiator: Exploration is manifested as specialization, the ability to identify and deliver customized services. Moreover, we found evidence of what we identified as 'exploration for exploitation', an orientation towards continually improving the quality of the service delivery, and 'exploration through exploitation', an approach of project-driven learning.

In each of the two companies, we found a culture of practices of project-based learning embedded in close, trustful and recurring customer relations. Bohn [5] recognizes the importance of organizational learning and notes that experience in executing a task generally leads to improvement in routine's enactment, a phenomenon associated with the concept of learning curves. According to the same author, organizational learning can be a directed activity, not just a by-product of normal production process and this supports our observations regarding ambidexterity mechanisms in both focal firms.

The first mechanism, exploration for exploitation corresponds to organizational learning as a directed activity while the second, exploration through exploitation corresponds to organizational learning as a byproduct of normal production process. Our data analysis suggests it is important for innovators in the IT services industry to create a minimum viable product, a basic product for learning purpose that helps organizations better understand the needs of their customers by seeking their feedback on the product in question $[30,22]$.

Our findings show that viadee's practices are based on idea prototyping or seeking input from its customers while trying to find innovative solutions to their problems and this is supported by the above-indicated literature. In our cases we found ambidextrous leadership, project team practices, and interorganizational relations. Framed by an overarching philosophy and well-nurtured culture of employee-orientation and empowerment - comparable to what [16] have characterized as 'engaging management' style, leadership has developed and aligned a repertoire of structural designs, policies and practices. We encountered enlightened and sensitive individuals (leaders) in our inter- 
views, who were well aware of the challenges of ambidexterity and aimed to balance exploitation ("billable hours') and freedom, even encouragement for exploration, e.g. training, personal development. Or even more pronounced, we found variations of an ambidextrous design of the work, which effectively enacts an espoused culture through the design of structures, policies and practices.

In general, the simultaneous use of exploitation and exploration has been considered a precursor of short- and long-term performance for firms. However, trade-off between exploitation and exploration as a result of the scarcity of resources, organizational routines, and power dynamics may cause ambidexterity to be a counterproductive strategy and firms may opt for specialization i.e. to exclusively focus on exploration or exploitation [33]. However, this strategy negatively affects a firm's performance.

On one hand, negligence of exploration prevents a firm from learning which in turn makes it obsolete and less competitive in the long run. On the other hand, exploratory activities require a lot of resources and focusing too much on exploration at the expense of exploitation can ultimately lead to a firm's bankruptcy [33].

So, balancing exploration and exploitation as the ambidexterity strategy found in our study has the support in the extant literature on the subject.

Table 3. Ambidextrous routines at the case companies

\begin{tabular}{|c|c|}
\hline Routines & Evidence and interpretation \\
\hline Exploitation & $\begin{array}{l}\text { Exploitation is the key mission of IT services companies. It dominates day-to-day routines and the revenue } \\
\text { stream, as evidenced by "billable hours" as key metric. }\end{array}$ \\
\hline Exploration & $\begin{array}{l}\text { Exploration is recognized as inevitable (due to IT innovation) and a critical differentiator from the competi- } \\
\text { tion. Yet it is recognized as challenging to establish an exploration mindset within an organization that has } \\
\text { billable hours as a key performance metric and the day-to-day pressure of demanding project work. Necessary } \\
\text { exploration is at risk of being crowded out by exploitation. } \\
\text { The tension between the two is quite present and pressing. It sets the stage for reflections on ambidexterity and } \\
\text { ambidextrous routines. }\end{array}$ \\
\hline $\begin{array}{l}\text { Structural } \\
A M B D\end{array}$ & $\begin{array}{l}\text { Structural ambidexterity is not prominent in the two case organizations. At best, it plays a role in the (interor- } \\
\text { ganizational) division of tasks between service provider and vendor: The vendors are regarded as responsible } \\
\text { for a large part of the product innovation. The service providers translate the innovation into the client organi- } \\
\text { zations. } \\
\text { Both case organizations have established structures and related practices, which set innovation (and R\&D) } \\
\text { apart and highlight it as distinctive: viadee has a head of R\&D, Noventum organizes a cross divisional "trend- } \\
\text { ing workshop" as part of the annual strategy meeting which focuses on assessing innovations in the market and } \\
\text { reflecting their potential for business development and positioning of the business units. } \\
\text { The practice of providing an R\&D budget also qualifies as structural ambidexterity: setting R\&D apart and } \\
\text { making resources available for it as a distinctive task. }\end{array}$ \\
\hline $\begin{array}{l}\text { Contextual } \\
A M B D\end{array}$ & $\begin{array}{l}\text { Management in both organizations makes a range of efforts to instill a sense of importance about ambidexter- } \\
\text { ity and specifically the linking and integration of exploitation and exploration into their teams, e.g. each em- } \\
\text { ployee at viadee is assigned to two managers, one to represent exploitation (projects, assignments ...), the } \\
\text { other exploration (personal development). } \\
\text { Both companies are subjecting themselves to the regular scrutiny of evaluation of the sensitivity to the needs } \\
\text { of their employees by "Great Place to Work ®". The certification is a recruitment and signaling instrument to } \\
\text { attract and retain the right type of talent, specifically it underscores a serious interest in the team members' } \\
\text { continuing education and further qualification (exploration). }\end{array}$ \\
\hline $\begin{array}{l}\text { Exploration } \\
\text { for exploita- } \\
\text { tion }\end{array}$ & $\begin{array}{l}\text { Both organizations put significant efforts into continuous improvements of their consultancy practices, starting } \\
\text { from the development of step-models up to systematically engaging with the client organization and their spe- } \\
\text { cific needs. We focus on a fairly narrow market segment and the high ratio of repeat business as evidence of } \\
\text { investment into exploration (capability building) as basis for exploitation. }\end{array}$ \\
\hline $\begin{array}{l}\text { Exploration } \\
\text { through ex- } \\
\text { ploitation }\end{array}$ & $\begin{array}{l}\text { Probably the most striking finding was the systematic use and indeed exploitation of projects for learning and } \\
\text { innovation. Projects are selected based on the learning potential (are they innovative, challenging?) so that the } \\
\text { project team can develop and hone skills, which they then can translate to other projects. viadee cultivates bot- } \\
\text { tom up idea collection for research initiatives based on client engagements. } \\
\text { We did not sense any concern on the side of the clients about this practice, on the contrary it seems to be wel- } \\
\text { come - surely reflecting the long lasting relationship with the case organizations - as the reciprocal structure } \\
\text { of this learning process is well understood: if the consultant learns at our project, they will do the same in other } \\
\text { projects and therefore will be more knowledgeable and competent. }\end{array}$ \\
\hline
\end{tabular}


We have identified a nuanced, multi-layered repertoire of ambidextrous routines (see Table 3). Thus, we have been able to highlight and classify a multiplicity of ambidextrous practices across the three levels of analysis: leadership, project team and client relations.

Beyond their consultant - client nature, the interorganizational relationships have been developed and are deployed as partnerships and arenas for learning. In other words, engaging with vendors and clients in a learning mode and learning relationships is part of the ambidextrous skill set and competence development, in line with an integrated view of ambidexterity. " $E x$ ploration can be when it's an innovative project in the area of the client, then we do a lot of knowledge development" (Division director 1, Noventum); "Some of our clients use it as a kind of protected playground to try out new ideas." (Senior consultant, viadee)

In his research on business partnerships, Lascaux [21] mentions the importance for organizations to maintain mutual trust and engage in repeated interactions with familiar partners and this has been observed in both case companies: "We have lots of long-term customers, with established trusted relationships. One client, the first sentence after the greeting was: ignore the contract, just look around and do something useful" (Senior consultant, viadee); "We are the hired chef that brings in a cook, servants, pots, pans, food, but we're cooking with a team that's made up of the client that is already using the kitchen, using a restaurant metaphor" (Division director 2, Noventum)

The service philosophy of both organizations highlights a holistic view of consultant - client relationship, which requires technically, methodically but also socially competent consultants. Project-driven learning serves both the client, as the service is refined, and the consultant, who achieves what we might call organic ambidexterity: learning and project execution are intricately linked. In this type of organizations, any effective transfer of knowledge is contingent upon the environment that gives employees psychological safety that allows them to share all relevant (unfiltered) information [2].

A number of factors can contribute to the creation of such enabling environment and a failure-tolerant leadership and a culture based on commitment to truth [2]. At Noventum, a failure-tolerant leadership is obvious and this is part of what explains the firm's success: “Don't look for the mistake, don't blame the mistake, look for the solution, push, push, push to the solution and don't dwell too long on mistakes" (Division director 3, Noventum).

Concerning project post-implementation review and the importance of a culture founded on truth and honesty, viadee's culture encourages blameless project post-mortem and this part of what explains the firm's success: "Blameless post-mortem: What happened, what went wrong and what went right, because you will better at managing the relationship with the customer" (Data scientist, viadee).

We also found prominent practices of cross-over, i.e. practices of not only complementing but refining one competence through the complementary one: exploration for exploitation and exploration through exploitation. Overall, a complex relational pattern and virtuous cycle has emerged:

1. Leadership has established an employee-focused and quality-oriented culture, which informs recruitment of talented and motivated consultants and project managers.

2. Specialization and long-term relationships with clients yield the acquisition (or assignment) of challenging and innovative projects, which provide extensive learning opportunities for the project team and yield job enrichment and satisfaction.

3. The learning in turn is not only rewarding for the team, but is continually translated, applied and challenged in other projects and extended in internal innovation practices, e.g. time for training, R\&D projects and cross-divisional exchanges. Thereby, an indirect or intermediated dissemination of experience happens within the client community.

4. The learning also happens at the cultural level: the project teams time and again set examples for competent and engaging project management and problem solving.

\section{Conclusions}

We have empirically explored 'ambidexterity inpractice and in situ' and developed a contextualized view on ambidextrous challenges and responses - at an organizational and interorganizational level in two IT service providers operating in a distinctive, competitive and innovation industry.

Our first contribution is thus an industry specific instantiation of ambidexterity, illustrating how the two firms adapted to their environment, shaped their value propositions and the underlying structures and processes of delivery. The findings illustrate elaborate management repertoires of interventions with respect to culture, structures, policies or practices, which are aligned with the ecosystem within which both companies are operating. Overall leadership has shaped successful project management and project execution practices, as projects are the settings of work, engagement with the clients and indeed learning and experimentation. Employee orientation is critical for employee retention in a tight labor market and a long- 
term perspective of continuous learning and honing of skills. Both companies have a strong employee focused culture.

Our second contribution is an integrated view on ambidexterity, which highlights specifically the benefits of exploration for exploitation. We have been linking the individual, the organizational and the interorganizational layer. Our findings, as expected, are highly contextualized and contingent upon the industry, positioning of the companies, and client organizations. They demonstrate successful differentiation as the raison d'être of the case companies, trying to escape the commoditization of their services ("clients have a choice"). This includes diverse approaches and routines to achieve ambidextrous capabilities.

The closer you look, the more the distinction between perfection at delivery on one hand, and continuous improvement, creativity, and innovation on the other hand, becomes blurred (cross-over between exploration and exploitation). We found a dominating commitment to outstanding consultancy services (exploitation) in a competitive environment. Recruiting, training, empowering and thereby retaining competent teams of consultants on the one side (Great Place to Work $($ ) and building and maintaining long-lasting, trusting relationships with the clients on the other, provide the setting not only for excellence in exploitation but also for distinctive ways of exploration.

We have identified and evidenced two instances of contextual ambidexterity: exploration for exploitation, in other words continuous improvement of service delivery, and exploration through exploitation, i.e. project-based or project-induced learning. Both have become honed as integral parts of the ambidextrous routines in the two case companies.

Obviously, our sample is small, yet we have carefully selected the two cases, which have demonstrated ambidextrous capabilities in a business environment, which is primarily driven by exploitation. At the time of the writing of this paper we finished interviewing several managers and consultants in a Canadian IT service provider with similar profile and structure as the two German companies. The next step will be to perform a geographical cross-case analysis to identify similarities and differences that will eventually provide interesting insights for practitioners from SMEs in the IT services industry on both sides of the Atlantic.

Absorptive capacity has been recognized as a construct closely linked to ambidexterity [6] and its operationalization reflects a process logic: acquire, assimilate, transform, exploit [33], which could be interpreted as the processual transition from exploration to exploitation. Thus, we see the relationship between organizational ambidexterity and absorptive capacity as a promising avenue to study the relationship between our case companies and their clients on one side, and their IT vendors on the other side.

\section{Acknowledgements}

The authors would like to gratefully acknowledge the Social Sciences and Humanities Research Council (CRSH) federal funding \#430-2018-00351 received for this project.

\section{References}

[1] P. Adler, B. Goldoftas, and D. Levine, "Flexibility versus efficiency? A case study of model changeovers in the Toyota production system," Organization Science, vol. 10, pp. 43-68, 1999.

[2] K. Ayas and N. Zeniuk, "Project-Based Learning: Building Communities of Reflective Practitioners," Management Learning, vol. 32, pp. 61-76, 2001.

[3] J. Birkinshaw and C. Gibson, "Building Ambidexterity into an Organization," MIT Sloan Management Review, vol. 45, pp. 47-55, 2004.

[4] J. Birkinshaw and K. Gupta, "Clarifying the distinctive contribution of ambidexterity to the field of organization studies," The Academy of Management Perspectives, vol. 27, p. 287, 2013.

[5] R. Bohn, "Measuring and Managing Technological Knowledge," Sloan Management Review, vol. 36, p. 61, 1994.

[6] R. Broersma, A. van Gils and A. Grip, "Ambidexterity in SMEs: Role of Absorptive Capacity and CEO's strategic engagement" in Academy of Management Proceedings, 2016.

[7] Y.-Y. Chang, M. Hughes, and S. Hotho, "Internal and external antecedents of SMEs' innovation ambidexterity outcomes," Management Decision, vol. 49, pp. 1658-1676, 2011.

[8] L. Dube and G. Paré, "Rigor in information systems positivist case research: current practices, trends, and recommendations," MIS Quarterly, vol. 27, pp. 597635, 2003.

[9] J. J. Ebben and A. C. Johnson, "Efficiency, flexibility, or both? Evidence linking strategy to performance in small firms," Strategic Management Journal, vol. 26, pp. 1249-1259, 2005.

[10] K. Eisenhardt, "Building Theories from Case Study Research," Academy of Management. The Academy of Management Review, vol. 14, p. 532, 1989.

[11] M. Feldman, "Organizational routines as a source of continuous change," Organization Science, vol. 11, pp. 611-629, 2000.

[12] M. S. Feldman and B. T. Pentland, "Reconceptualizing Organizational Routines as a Source of Flexibility and Change," Administrative Science Quarterly, vol. 48, pp. 94-118, 2003.

[13] M. Feldman and W. Orlikowski, "Theorizing Practice and Practicing Theory," Organization Science, vol. 22, pp. 1240-1253, 2011.

[14] M. S. Feldman, B. T. Pentland, L. D'Adderio, and N. Lazaric, "Beyond routines as things: Introduction to 
the special issue on routine dynamics," Organization Science, vol. 27, pp. 505-513, 2016.

[15] C. Gibson and J. Birkinshaw, "The antecedents, consequences, and mediating role of organizational ambidexterity," Academy of Management Journal, vol. 47, pp. 209-226, 2004.

[16] J. Gosling and H. Mintzberg, "The five minds of a manager," Harvard Business Review, vol. 81, pp. 5463, 2003.

[17] A. Gupta, K. Smith, and C. Shalley, "The interplay between exploration and exploitation," Academy of Management Journal, vol. 49, pp. 693-706, 2006.

[18] L. Heracleous, A. Papachroni, C. Andriopoulos, and M. Gotsi, "Structural Ambidexterity and Competency Traps: Insights from Xerox Parc," Technological Forecasting and Social Change, vol. 117, pp. 327338, 2017.

[19] J. A. Howard-Grenville and C. Rerup, Handbook of Process Organizational Studies. Thousand Oaks: SAGE Publications, 2017.

[20] O.-P. Kauppila, "Creating ambidexterity by integrating and balancing structurally separate interorganizational partnerships," Strategic Organization, vol. 8, pp. 283-312, 2010.

[21] A. Lascaux, "Absorptive Capacity, Research Output Sharing, and Research Output Capture in UniversityIndustry Partnerships," Scandinavian Journal of Management, 2019.

[22] O. Lorenzo, P. Kawalek and L. Wharton, Entrepreneurship, Innovation and technology: A guide to core models and tools. New York: Routledge, 2018

[23] M. H. Lubatkin, Z. Simsek, Y. Ling, and J. F. Veiga, "Ambidexterity and Performance in Small-to Medium-Sized Firms: The Pivotal Role of Top Management Team Behavioral Integration," Journal of Management, vol. 32, pp. 646-672, 2006.

[24] J. G. March, "Exploration and Exploitation in Organizational Learning," Organization Science, vol. 2, pp. 71-87, 1991.

[25] M. B. Miles, A. M. Huberman and J. Sardana, Qualitative Data Analysis: A Methods Sourcebook. Los Angeles, CA: SAGE Publications, 2013

[26] Noventum, IT Management Consulting. Retrieved July 08, 2020, from Noventum: https://www.noventum.delen/

[27] C. A. O'Reilly and M. L. Tushman, "Organizational ambidexterity: past, present, and future," The Academy of Management Perspectives, vol. 27, p. 324, 2013.

[28] B. T. Pentland and M. S. Feldman, "Organizational routines as a unit of analysis," Industrial and Corporate Change, vol. 14, pp. 793-815, 2005.

[29] C. Rerup and M. S. Feldman, "Routines as a source of change in organizational schemata: The role of trialand-error learning," Academy of Management Journal, vol. 54, pp. 577-610, 2011.

[30] M. Schulz, "Organizational learning," The Blackwell Companion to Organizations, pp. 415-441, 2017.
[31] C. Senaratne and C. L. Wang, "Organizational ambidexterity in UK high-tech SMEs: An exploratory study of key drivers and barriers," Journal of Small Business and Enterprise Development, vol. 25, pp. 1025-1050, 2018.

[32] M.F.R. Alves, S.V.R. Galina, and S. Dobelin, "Literature on organizational innovation: past and future," Innovation \& Management Review, vol. 15, pp. 2-19, 2018.

[33] M. Solís-Molina, M. Hernández-Espallardo, and A. Rodríguez-Orejuela, "Performance implications of organizational ambidexterity versus specialization in exploitation or exploration: The role of absorptive capacity," Journal of Business Research, vol. 91, pp. 181-194, 2018.

[34] H. Tanriverdi and V. Uysal, "Cross-Business Information Technology Integration and Acquirer Value Creation in Corporate Mergers and Acquisitions," Information Systems Research, vol. 22, pp. 703-720, 2011.

[35] viadee, "Culture, Methodology, and Industry Experience as an Inseparable Unit," Retrieved July 08, 2020 from viadee: https://www.viadee.delen/company/philosophyl

[36] G. B. Voss, and Z. G. Voss, "Strategic ambidexterity in small and medium-sized enterprises: Implementing exploration and exploitation in product and market domains," Organization Science, vol. 24, pp. 1459-1477, 2013.

[37] D. Vrontis, A. Thrassou, G. Santoro, and A. Papa, "Ambidexterity, external knowledge and performance in knowledge-intensive firms," Journal of Technology Transfer, vol. 42, pp. 374-388, 2017.

[38] C. L. Wang and M. Rafiq, "Ambidextrous Organizational Culture, Contextual Ambidexterity and New Product Innovation: A Comparative Study of UK and Chinese High-tech Firms," British Journal of Management, vol. 25, pp. 58-76, 2014.

[39] R. K. Yin, Qualitative Research from Start to Finish. New York: Guildford Publications, 2015.

[40] C. Yoon, K. Lee, B. Yoon, and O. Toulan, "Typology and success factors of collaboration for sustainable growth in the it service industry," Sustainability, vol. 9, pp. 1-20, 2017.

[41] S. Wuyts, and S. Dutta, S, "Benefiting from alliance portfolio diversity: The role of past internal knowledge creation strategy," Journal of Management, (40:6), pp. 1653-1674, 2014.

[42] S.A. Zahra, "Governance, ownership, and corporate entrepreneurship: The moderating impact of industry technological opportunities," Academy of Management Journal, vol. 39, pp. 1713-1735, 1996.

[43] C.A. O'Reilly and M. L. Tushman, "Ambidexterity as a dynamic capability: Resolving the innovator's dilemma," Research in Organizational Behavior, vol. 28, pp. 185-206, 2008. 